\title{
Aquifer vulnerability assessment in the Bengal alluvial tract, India, using GIS based DRASTIC model
}

\author{
Tathagata Ghosh $^{1} \cdot$ Rolee $\operatorname{Kanchan}^{1}$ (D)
}

Received: 20 June 2016/ Accepted: 29 July 2016/Published online: 9 August 2016

(C) Springer International Publishing Switzerland 2016

\begin{abstract}
In the present study, an attempt has been made to evaluate the aquifer vulnerability in the central part of Bengal alluvial tract, covering $5324 \mathrm{~km}^{2}$ area by using DRASTIC model. Seven critical hydrogeological factors were taken into consideration. Initially, vulnerability index of individual factors were calculated on the basis of predefined weights and ratings. These indices were further combined to depict the actual vulnerability of the region. The model comprised of seven spatial parameters and their attributes and in handling of such diverse datasets, GIS played a significant role. For the depiction of the subsurface lithological characteristics, subsurface lotho-log data were used to generate 3 dimensional fence diagram of the entire region which was further helped in depicting the aquifer media condition. Entire eastern region of river Bhagirathi, a distributary of river Ganga, showed higher vulnerability index, which was about $29.65 \%$ of the total study area, while the western portion had lesser vulnerability. Along with conventional modeling, map removal sensitivity analysis was also incorporated to examine the impact of different factors on the entire model. Depth to the water and impact of vadose zone were two important factors that contributed $46.93 \%$ of the total variability of the model. Further, the generated model was incorporated with the locations of 156 groundwater samples, collected from the entire region and concentration of arsenic was determined to understand the probable relationship with the generated model through correlation coefficient. The model
\end{abstract}

Rolee Kanchan

roleekanchan@gmail.com

1 Department of Geography, Faculty of Science, The Maharaja Sayajirao University of Baroda, Vadodara 390002, Gujarat, India presented in the paper depicted recent hydrogeochemical condition of the aquifer which might help in further management of the region.

Keywords Bengal alluvial tract · DRASTIC . Vulnerability index $\cdot$ Single map removal technique . Aquifer

\section{Introduction}

Groundwater has great potential in terms of its utility throughout the world. After confirmation by World Health Organization (WHO) about its safety, the uses have amplified to a great extent (Ravenscroft et al. 2009). Drinking, domestic, agriculture and industrial activities are few areas, where groundwater is widely being used. Inspite of its great importance, it became a great threat because of its sensitivity to different contaminants. Thus, it is necessary to examine the water quality to ensure its safe usability. Groundwater is the function of number of physico-chemical responses, thus it is important to incorporate vital parameters in a model that can give meaningful and timely result so that proper management can be taken. Several models of aquifer vulnerability have been developed and proposed by different scholars. GOD model was developed by Foster (1987), where groundwater occurrence, overall aquifer class and depth table of the groundwater was taken into considerations. SINTACS model by Civita and De Maio (2004) was comprised of parameters like groundwater table depth, actual infiltration, self-depuration effect of unsaturated zone, overburden type, hydrogeological characteristics of the aquifer, hydraulic conductivity and topographical surface slope. AVI model proposed by Van Stempvoort et al. 
(1992) was based on two parameters viz. thickness of each sedimentary unit above the uppermost aquifer and estimated hydraulic conductivity of each of these layers. U.S. Environmental Protection Agency (EPA) developed a model based on different groundwater parameters having different weight and rating with corresponding range of groundwater to depict groundwater pollution potential (US EPA 1985) and known as DRASTIC model. Seven critical parameters of groundwater viz. depth (D), net recharge (R), aquifer media (A), soil (S), topography (T), impact of vadose zone (I) and hydraulic conductivity (C) are incorporated in it. Among these models, DRASTIC is extensively used by different scholars for its robustness, simplicity and relatively ease of availability of required data.

Wen et al. (2009) carried out groundwater vulnerability assessment in the shallow groundwater of Zhangye basin of northwestern China using DRASTIC model applying GIS. On the basis of the analysis, the entire region was classified into three zones of vulnerabilities and it was found that important cities with higher to medium groundwater vulnerability were located near groundwater recharge zone. Chitsazan and Akhtari (2009) worked on the similar lines and focused on the GIS based DRASTIC modeling in the Kherran plain of Iran. In association with the conventional modeling, concentration of nitrate in the groundwater was also incorporated and it was observed that southwest and western part of the study area had higher concentration of the elements. Fraga et al. (2013) incorporated multivariate statistical structure with the DRASTIC model in Sordo river basin located in the north east of Portugal. In this study, composite index was based on three parameters namely topography, recharge and aquifer material and termed as vector-matrix. The result also indicated that, Sordo river basins, as an environment, had self-capability to neutralize pollutants. Panagopoulos et al. (2006) had redefined all the factor ratings and weights of contemporary DRASTIC model under GIS environment and also incorporated statistical and geostatistical techniques into it. The study was conducted in the Trifilia province of Greece and the results showed that after modifications in the model the correlation coefficient between the groundwater pollution risk and nitrite concentration increases to considerable level. Rahman (2008) focused on the groundwater vulnerability assessment in the Aligarh city, Uttar Pradesh, India, using similar approach and groundwater parameters like copper, zinc and lead of different wells were also included. The results depicted the fact that, $>80 \%$ of the groundwater was under the category of medium to high vulnerability index. Similar type of approach has been adopted by Babiker et al. (2005). He applied DRASTIC model in the Kakamigahara Heights, Gifu prefecture of central Japan. It was concluded that removal of net recharge, soil media and topography layers caused considerable variations in the entire model. Further he also incorporated land use pattern in the model where intensive agriculture was found to be one of the controlling factor. Herlinger and Pedro (2007) adopted similar approach in their study to assess groundwater vulnerability in the coastal plains of the Rio-Grande do Sul of Brazil. Ions like copper, lead, sulfate and phosphate were incorporated in the model. It was found in the study that, sediment size played an important role in the mobility of the contaminants. Fritch et al. (2000) assessed aquifer vulnerability in the Paluxy aquifer, central Texas of USA using same model. Result indicated the fact that $47 \%$ of the study area was under low pollution potential while $27 \%$ showed higher vulnerability. Assaf and Saadeh (2008) also focused on the DRASTIC model in association with geostatistical assessment of groundwater with nitrate concentration of upper Litani Basin of Lebanon. In the study it was found that nitrate level was much higher than the standard limits in different parts of the basin. Further they also incorporated Kriging method and found that it was an important tool to depict spatial distribution of the nitrate. Lee (2003) applied the similar model in his study to evaluate the waste disposal sites in South Korea. In this study, modified DRASTIC model was developed in association with the lineament density for fractured aquifer. Groundwater is being harnessed for the last several decades for diverse purposes in different parts of the world including India. Thus, to ensure safe and potable groundwater it is necessary to evaluate the aquifer conditions through proper method. In the present study, an effort has been made to appraise the aquifer vulnerability in the central Bengal alluvial tract through DRASTIC model proposed by US EPA. Seven hydrogeological parameters viz. depth to the water, net recharge, aquifer media, soil media, topography, impact of vadose zone and hydraulic conductivity were incorporated. Along with the generation of conventional model, Map Removal Sensitivity Analysis (MRSA) and concentration of arsenic in different seasons was also incorporated to depict probable reason behind present aquifer condition.

\section{Materials and methods}

\section{Study area}

The present study comprised of $5324 \mathrm{~km}^{2}$ area $\left(23^{\circ} 43^{\prime} 30^{\prime \prime} \mathrm{N}\right.$ to $24^{\circ} 50^{\prime} 20^{\prime \prime} \mathrm{N}$ latitude and $87^{\circ} 46^{\prime} 17^{\prime \prime} \mathrm{E}$ to $88^{\circ} 46^{\prime} 00^{\prime \prime} \mathrm{E}$ longitude) and located in the central part of Bengal alluvial tract, West Bengal, India (Fig. 1) (District Census Hand Book 2001). It adjoins international boundary with Bangladesh in the east; in the west and south it is surrounded by the 


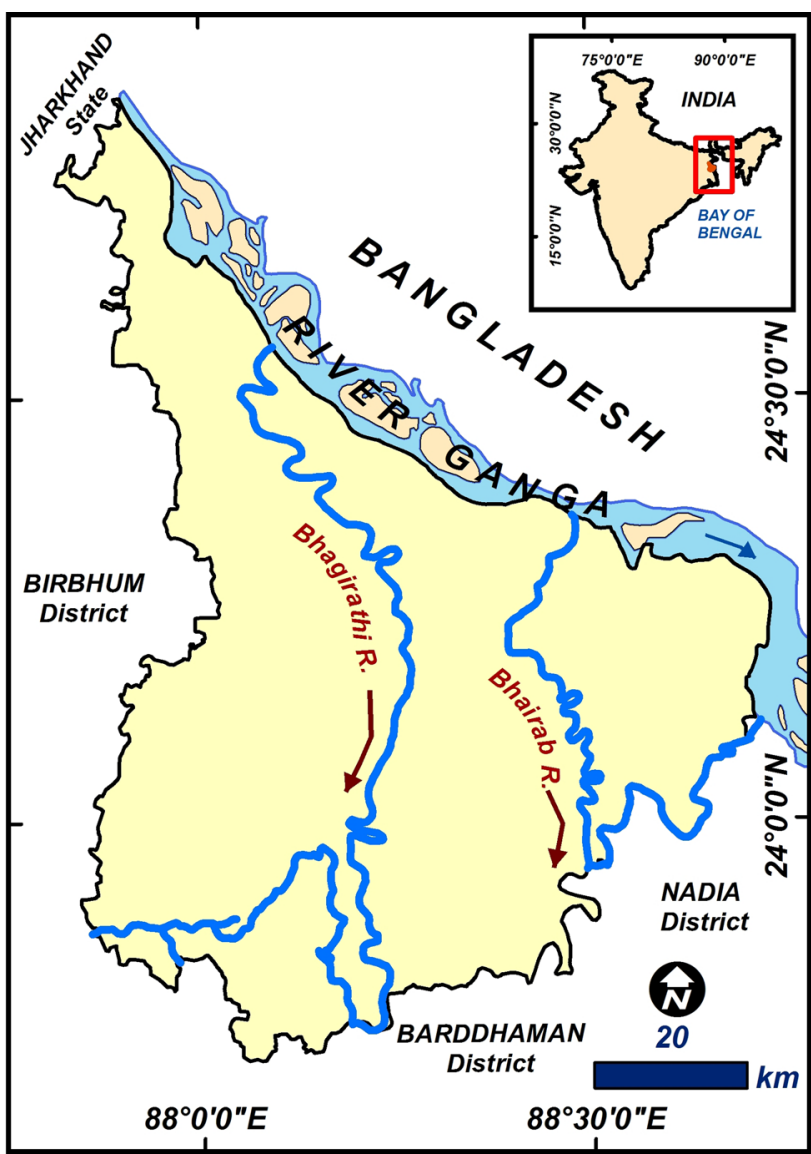

Fig. 1 Location map of the study area

districts of West Bengal viz. Birbhum, Barddhaman and Nadia respectively. In the north western portion, it shares the state boundary with Jharkhand. The entire region is almost flat as the elevation ranged between $10-50 \mathrm{~m}$ above mean sea level (District Census Handbook 2001).

\section{Hydrogeological condition}

The hydrological characteristic of the entire region is governed by the river Ganga, its number of tributaries and distributaries. It flows along the northern margin from northwest to south east direction. It showed highly meandered path associated with the formation of channel bars in the upper reaches, while in the eastern portion the channel gets contracted. Bhagirathi is an important distributary of it that flows in central portion of the study area from north to south direction. In the east, river Bhairab also follows the similar path in meandered pattern. The entire region is associated with three types of aquifer systems. Western portion of river Bhagirathi comprised older alluvium and related to silt, sand, gravel and pebbles of Upper Tertiary period showing the characteristics of thick semiconfined condition. Eastern portion is composed of clay, silt, sand and gravel where impervious clay layer is rather absent showing the thick unconfined condition. In the northwestern tip, a small patch of rajmahal trap of basaltic rock is situated with unconfined situation (Groundwater Information Booklet 2007) (Fig. 2a). Due to absence of any significant impermeable layer, the saturated zone of groundwater is found even to the depth of $150 \mathrm{~m}$. At very shallower depth $(2-5 \mathrm{~m})$ generally water table is found with higher groundwater potential [ $>42$ yield (L/s)] (District Planning Map Series 2002). Rampurhat, Kandi and Bhagirathi are the three major stratigraphic formations found in this region and comprised of quaternary sediments. Rampurhat formation is mainly situated in the western portion of the study area and associated with hard clays impregnated with caliche nodules. Kandi formation is more extensive in the eastern segment that consists of alternating layers of sand, silt and clay while Bhagirathi formation occupies the present day flood plains and comprised of alluvial soil. Only a small patch of Rajmahal trap of basaltic rock is situated in the north western tip (District Resource Map 2008) (Fig. 2b).

\section{Data and sample collection}

For the creation of the model all the necessary data were collected from the government and non-government agencies. The sources of secondary data were as follows:

Depth to the water data along with the longitude and latitude of the observation wells for 2010 was collected from the Groundwater Authority Board of India website (http://gis2. nic.in/cgwb/Gemsdata.aspx, http://www.india-wris.nrsc.gov. in/GWLevelApp.html? UType=R2VuZXJhbA==?UName=). Net Recharge data was derived from the Groundwater Year Book 2010-11 (http://www.cgwb.gov.in/documents/sites/ indiawaterportal.org/files/murshidabad.pdf) and District resource map of Murshidabad district (District resource map of Murshidabad 2008). Aquifer media layer was prepared from bore-well log data collected from Public Health Engineering Department (PHED) of Murshidabad and non government agencies. All the data were incorporated in Rock Works software to prepare fence diagram of the region. Soil media layer was prepared from the data of National Bureau of Soil Survey and Landuse planning, Kolkata. Topography layer was generated from the $30 \mathrm{~m}$ SRTM data downloaded from http://glcfapp.glcf.umd.edu:8080/esdi/index.jsp and slope of the land was derived in respect to $\%$. Impact of vadose zone layer was generated from subsurface lithological data from bore well logs collected from the PHED, Murshidabad and non-government agencies. Hydraulic conductivity layer was generated from the transitivity data were obtained from the Murshidabad information booklet (http://www.indiawa terportal.org/sites/indiawaterportal.org/files/murshidabad. pdf). After collection of the data, the rates and weights of different parameters are given as follows (US EPA 1985) (Tables 1,2). 
a

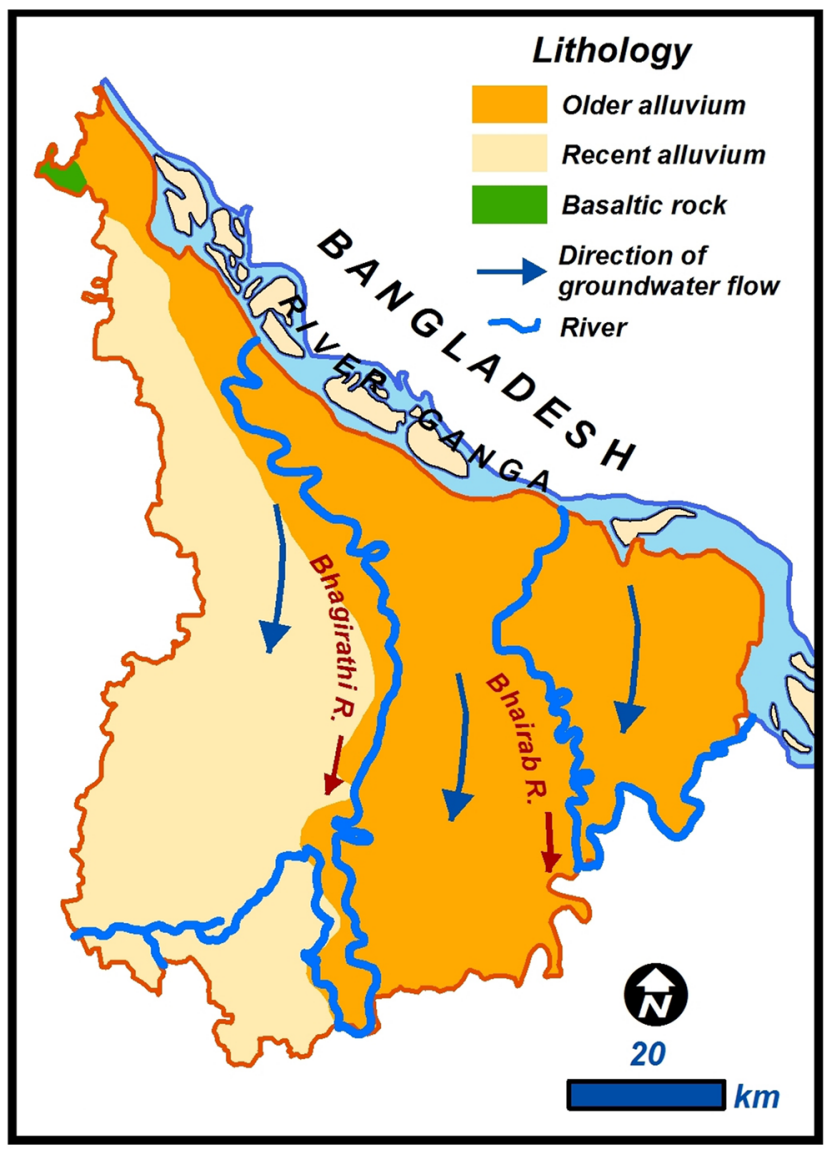

b

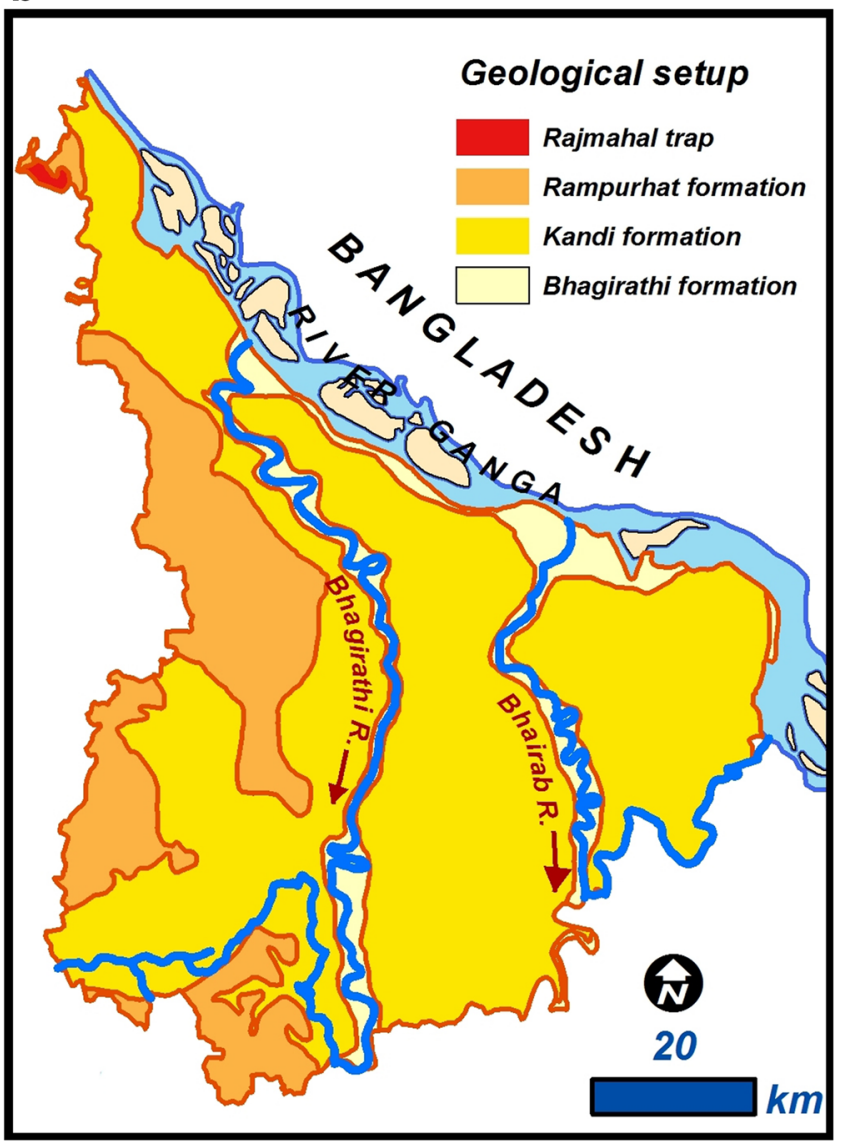

Fig. 2 a Lithology and direction of groundwater flow of the study area (Source: Groundwater Information Booklet 2007). b Geological setup of the study area (Source: District Resource Map 2008)

130 randomly selected groundwater samples were collected from the shallow depth through hand pumps that covered the entire study area. Sampling locations were marked by using hand held GPS (Garmin eTrex Vista HCx) and thereafter downloaded to the computer using Mapsource software. From the same wells, samples were collected for three seasons i.e. premonsoon, monsoon and postmonsoon of 2010. Before collection of the samples, hand pump was rigorously pumped to clean the inner portion of the pipe. The water samples were collected in

Table 1 Assigned weights of each parameters [Source: U.S. EPA (1985)]

\begin{tabular}{ll}
\hline Factors & Weights \\
\hline Depth to water & 5 \\
Net recharge & 4 \\
Aquifer media & 3 \\
Soil & 2 \\
Topography & 1 \\
Impact of vadose zone & 5 \\
Hydraulic conductivity & 3 \\
\hline
\end{tabular}

$500 \mathrm{ml}$. polyethylene terephthalate (PET) bottles, acidified with $\mathrm{HCl}$ and retained under low temperature. The concentration of arsenic was analysed in the government recognized water testing laboratory by professionals (Southern Health Improvement Samiti, South 24 Parganas, West Bengal).

Evaluation of site specific groundwater contamination under a particular hydrogeological setting is the major objective of this numerical rating scheme. The equation of the model involves multiplication of the every factor with its weights and rating followed by the summation of the total (Knox et al. 1993). For computing the pollution potential, composite vulnerability index was calculated from the following linear Eq. (1).

$$
\begin{array}{r}
D_{r} D_{w}+R_{r} R_{w}+A_{r} A_{w}+S_{r} S_{w}+T_{r} T_{w}+I_{r} I_{w} \\
+C_{r} C_{w}=\text { Pollution potential (DRASTIC) }
\end{array}
$$

where $\mathrm{r}$ is the rate, $\mathrm{w}$ is the weight, $\mathrm{D}$ is the depth to groundwater, $\mathrm{R}$ is the recharge, $\mathrm{A}$ is the aquifer media, $\mathrm{S}$ is the soil media, $\mathrm{T}$ is the topography, $\mathrm{I}$ is the impact of vadose zone, $\mathrm{C}$ is the hydraulic conductivity. 
Table 2 Rating system for different factors [Source: U.S. EPA (1985)]

\begin{tabular}{|c|c|c|c|c|c|}
\hline \multicolumn{2}{|c|}{ Depth (D) (Feet) } & \multicolumn{2}{|c|}{ Net recharge $(\mathrm{R})$ (Inches) } & \multicolumn{2}{|l|}{ Aquifer media (A) } \\
\hline Range & Rates & Range & Rates & Range & Typical rating \\
\hline$<5$ & 10 & $7-10$ & 8 & Fine to medium sand & 5 \\
\hline $5-15$ & 9 & & & Coarse sand & 8 \\
\hline 15 and $>$ & 7 & & & & \\
\hline \multicolumn{2}{|l|}{ Soil (S) } & \multicolumn{2}{|c|}{ Topography (T) (\% slope) } & \multicolumn{2}{|l|}{ Impact of vadose zone (I) } \\
\hline Range & Rate & Range & Rate & Range & Rate \\
\hline Sandy loam & 6 & $<18$ & 3 & Sand and gravel with significant silt and clay & 6 \\
\hline Loam & 5 & 18 and $>$ & 1 & Sand and gravel & 8 \\
\hline \multicolumn{6}{|c|}{ Hydraulic conductivity $\left(\mathrm{GPD} / \mathrm{FT}^{2}\right)(\mathrm{C})$} \\
\hline \multicolumn{4}{|l|}{ Range } & & Rate \\
\hline \multicolumn{4}{|l|}{$1000-2000$} & & 8 \\
\hline
\end{tabular}

In this model, the rating system is developed by using Delphi technique proposed by Aller et al. 1987. The rating scheme is well established and been used worldwide in number of studies (Chandrashekhar et al. 1999; Napolitano 1995; Napolitano and Fabbri 1996; Margane 2003; Anwar et al. 2003; Dixon 2005). The rating of each of the factors in the model is variable to apply this model in different site specific conditions (Dixon 2005) while the weights of the factors are fixed. The weights of the factors in the model are established on the basis of practical, logical and research experiences. The weights varies between $1-5$ where former is related to least risk while later means highest risk. In the present model two factors (depth and impact of vadose zone) were given highest weights while the topography has least weight. Hydrogeologically the present study area is associated with low topography and thick alluvial deposits. Precipitation in this region is abundant and groundwater table is generally shallow. On the basis of the following characteristics, the ratings for each of the factors were adopted (US EPA 1985).

In DRASTIC model, each of the factors has their own importance. Thus, it is necessary to depict the impact of each of the parameter on the whole model. To perform this operation, Map Removal Sensitivity Analysis (MRSA) technique was adopted where every time a single factor is removed and its impact on the entire model in-terms of variability is computed. For the calculation of variation index, Eq. (2) formulated by Napolitano and Fabbri (1996) was adopted.

$V_{\text {arix }}=\frac{V_{i}-V_{x i}}{V_{i}} \times 100$

where $V_{\text {arix }}$ is the variation Index, $V_{i}$ is the vulnerability Index using Eq. (1) on the sub area, $V_{x i}$ is the vulnerability index of the subarea excluding one map layer.

\section{Spatial representation}

Arc GIS 10.2 software was used in this study to generate the model. On the base map of the study area, depth to the water data was plotted along with its corresponding locations and attributes. Interpolation was done on the basis of the inverse distance weighting (IDW) method. After generation of the layer, it was converted into vector format. For the creation of aquifer media and impact of vadose zone layer, litho-log data were used and subsurface lithological model was generated by using Rock Works 15 software. Attributes of litho-logs, in terms of their corresponding locations, depth, lithology and colour; were incorporated into the software and 3 dimensional fence diagram was prepared from the best possible viewing angle. Further the results obtained, were vectorized in Arc GIS. Soil media layer was produced by simply vectorizing the acquired soil map. For the creation of topography layer, slope map was created from SRTM data. On the basis of elevation, the entire region was classified into two classes $(<18 \%$ and $>18 \%$ slope $)$ and vectorized in GIS. As net recharge and hydraulic conductivity showed uniform condition throughout the region, the outer boundary of the study area was vectorized and corresponding data was incorporated into it. All the layers were attributed with their corresponding vulnerability indices, the layers were converted into raster format and all the raster layers were combined together for calculating the pollution potential by using raster calculator. Further, all the layers were converted into vector format and superfluous portion were eliminated through erase function. Further, and all the layers were combined to each other to convert them into single layer. The vulnerability indices of the entire study area were classified into five classes. 
The locations of the sampling wells and the concentration of the arsenic were incorporated in the model. The locations were further classified into three categories on the basis of their arsenic concentration $(<0.05,0.05-0.20$ and $>0.20 \mathrm{mg} / \mathrm{l}$ ). For establishing relationship between arsenic concentration with DRASTIC variables, correlation analysis has been done where vulnerability indices and the arsenic concentration were taken into considerations.

\section{Results and discussion}

\section{Depth to the water}

Depth to the groundwater is an important parameter as it determines the time taken by the contaminant before mixing with the groundwater. As the distance between the surface and the groundwater table increases, the travel time of the contaminant increases while lesser difference between the surface and the groundwater table indicates lesser travel time of the contaminants to mix with the groundwater (Babiker et al. 2005). In 2010, it was observed that, in the eastern portion of the region, it was relatively shallower $(<5 \mathrm{mbgl})$ while in the western portion it was relatively greater (5-15 and $>15 \mathrm{mbgl}$ ) (Fig. 3a). Eastern segment of the region showed higher vulnerability index (50) while the western portion had a vulnerability index of 35 . In the central west segment, two small patches showed vulnerability index of 45 . It was observed that, $58.27 \%$ of the total area was associated with high vulnerability $(<5$ mbgl), $2.08 \%$ was under medium vulnerability (5-15 $\mathrm{mbgl}$ ) and $39.65 \%$ was related to low vulnerability zone $(>15 \mathrm{mbgl})$. The result depicted the fact that, susceptibility of groundwater associated with depth to the water increased from west to eastern portion of the study area.

\section{Net recharge}

Net recharge is defined by the total amount of water that penetrates to groundwater from precipitation, surface and all other sources (Todd and Mays 1980). The rate of recharge increases with the increasing precipitation and availability of surface water like rivers. In terms of relative weight (4) it is next to depth. There is a positive relationship between the rate of recharge and higher rate of movement of contaminates. In the study area the higher amount of rainfall

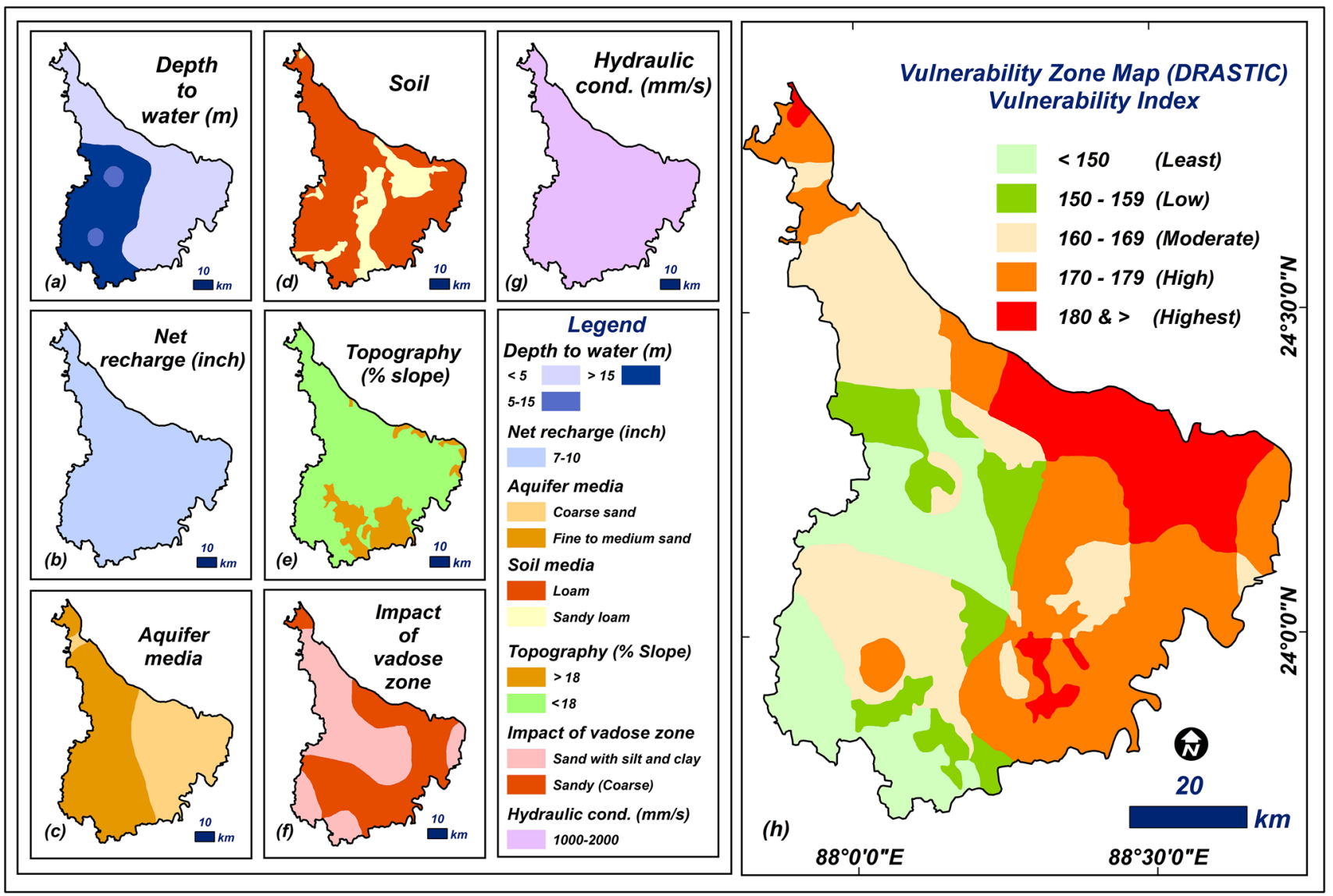

Fig. 3 Aquifer vulnerability model (DRASTIC) 


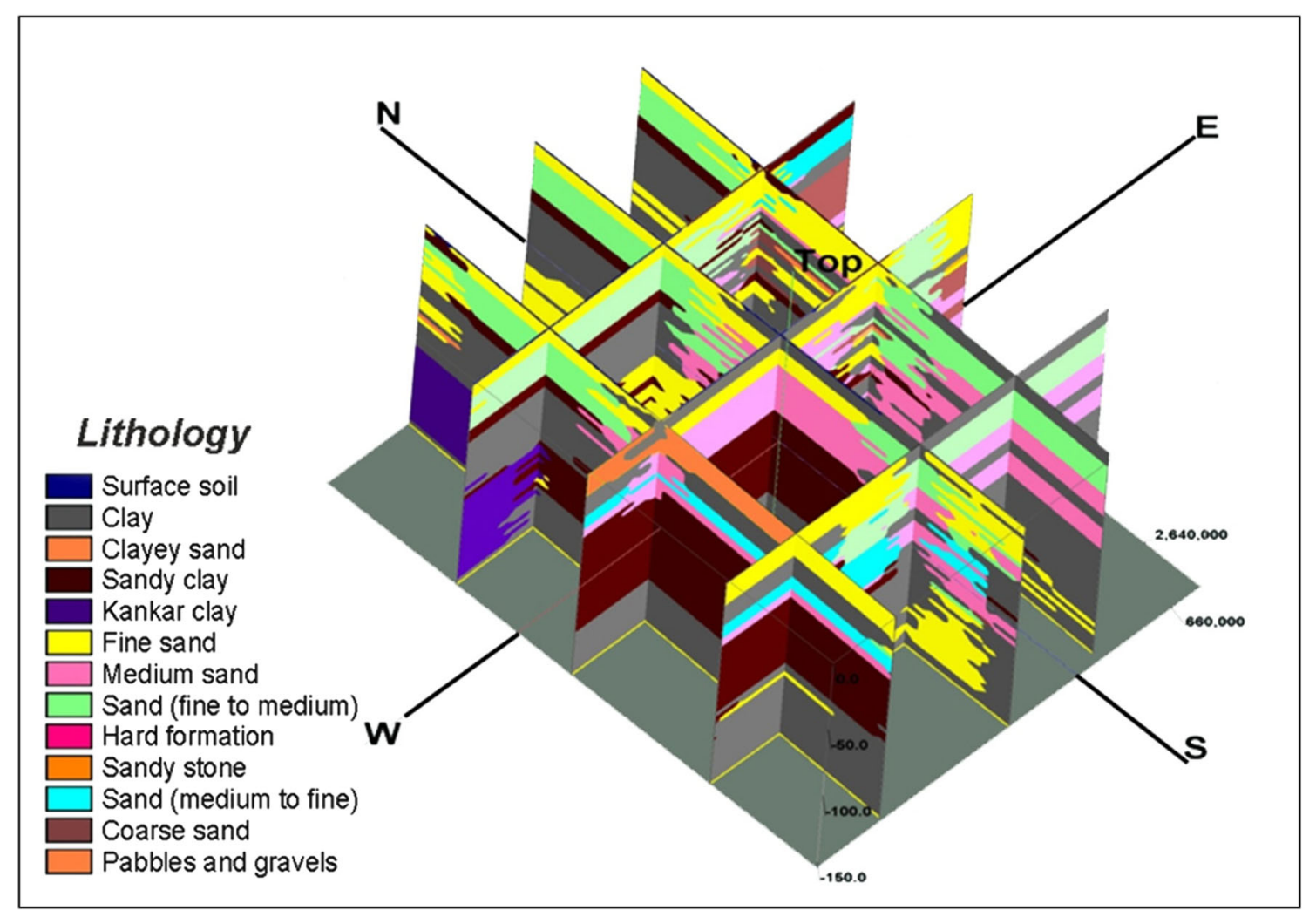

Fig. 4 Subsurface lithological fence diagram

$(1600 \mathrm{~mm})$ and presence of river Ganga its numerous tributaries and distributaries are two important factors that contributed in higher rate of recharge (7-10 inches). The calculated vulnerability index of net recharge was 32 and evenly distributed throughout the region (Fig. 3b).

\section{Aquifer media}

Aquifer media is the characteristics of materials by which the aquifer is made of (Chitsazan and Akhtari 2009). For the understanding of the aquifer media, it is necessary to understand the subsurface lithological condition. To attain subsurface lithological condition, lithologs were taken into considerations and further the model was generated (Figs. 3c, 4). The generated model depicted the fact that, the aquifer is mainly composed of fine/medium sand and course sand type of materials. Rate of infiltration is generally decreases as the sediments gets finer. On the other hand, as the space between the particles is more the infiltration of water would be easier. Thus, it can be deduced that, as the aquifer media gets finer the vulnerability is lesser while the coarser texture of media is associated with higher vulnerability. After applying appropriate rating and weight, it was found that the eastern portion of the region depicted vulnerability index 24 which is associated with coarser aquifer media while the western portion showed vulnerability index of 15 having finer texture. $43.11 \%$ of the entire region depicted higher vulnerability while $56.89 \%$ of the region was under low vulnerability zone.

\section{Soil}

Soil is considered to be an important parameter as it is the first layer through which water infiltrates into the subsurface. As the soil texture become finer the space between the soil particles decreases and the rate of infiltration decreases while as the texture becomes coarser the infiltration rate increases (Hvorslev 1951). Entire study area comprised of loamy and coarse sandy type of soil. In the central portion of the region a continuous patch of sandy loam were observed. In the north east and in the western part small patches of sandy loam was observed. Rest of region was associated with fine loams (Fig. 3d). The results showed that $19.13 \%$ of the total area had higher vulnerability (12) while the rest of the region $(80.87 \%)$ was associated with considerably lower index (10).

\section{Topography}

Topography is the surface configuration in terms of elevation. In this model, topography is assigned with least 
weight (1). The slope of the land determines the rate of movement of water on the land surface. As the slope of the land increases the movement of water also increases hence infiltration rate decreases. Contrarily, as the slope of the land decreases, the movement of water decreases hence the infiltration rate increases. The entire study area is associated with flat topography or plain. Some small patches of regions has a slope of $>18 \%$ while rest of the region has $<18 \%$ of slope (Fig. 3e). The regions with slope $>18 \%$ had vulnerability index of 3 and covered $16.29 \%$ of the total area while regions with slope $<18 \%$ was associated with vulnerability index of 1 covering $83.71 \%$ of the total area.

\section{Impact of vadose zone}

Unsaturated zone between the surface and the groundwater table is the vadose zone (Todd and Mays 1980). The condition of the zone is quite complex as the geochemical condition of the region and the transport of the contaminants plays an important role in determining the condition of the groundwater. Due to the complex nature of the region, the parameter was given high relative weight (5). The characteristics of this parameter is similar to the soil. As the materials in the vadose zone gets coarser the rate of infiltration increases while as the materials gets finer the rate of infiltration decreases. The characteristics of the vadose zone was depicted from the subsurface litho-logical model. The eastern, northern and southern portion of the region had a continuous patch of sandy (coarse) materials while in the western portion the materials comprised of sand with silt and clay (finer) (Fig. 3f). Thus, it can be inferred that the eastern, northern and southern portion of the region is associated with higher vulnerability index (40) covering an area of $49.97 \%$ while the western portion is composed of relatively finer material which restricts the penetration of water and depicted lesser vulnerability (30) with an area of $50.03 \%$.

\section{Hydraulic conductivity}

It is the capacity of water to transmit water from one place to another (Saha and Alam 2014). It is a significant parameter as it is associated with rate of flow and movement of contaminants. The significance of the parameter can be comprehended from its higher weight (3) in the model. The vulnerability index was calculated from the transitivity data (24) and it was found to be evenly spread over the entire region (Fig. $3 \mathrm{~g}$ ).

\section{DRASTIC vulnerability index}

All the seven parameters were combined and the pollution potential was calculated. The indices were classified into five classes namely "least", "low", "moderate", "high" and "highest" vulnerability. The entire eastern portion of river Bhagirathi was associated with "high" and "highest" vulnerability indices ranging from 160 to 180 and $>$, while in the western portion it varied between $<150$ to 169 . The region with highest vulnerability index $(>180)$ was observed in the north central portion of the study area while some discontinued patches were also observed in the southern and north western tip of the region. The next class was between 171 and 180 that distributed in the eastern and southern portion of the study area. Few small patches were observed in the north western portion of the study area. Moderate vulnerability index (160-169) was observed in the western portion of the area. A small patch of the same was also found in the eastern portion of the region. Remaining two classes $(<150$ and $150-159)$ were situated in the west central and south western portion of the study area (Fig. 3h). In terms of area coverage, two categories viz. high, having vulnerability index varied between 170 and 179 and moderate with vulnerability index ranged between 160 and 169 covered $56.22 \%$ of the total area together (Table 3 ). Highest category of vulnerability index depicted $14.13 \%$ of the total area. Last two categories (low and least) depicted 10.24 and $19.41 \%$ of the total area.

\section{Map removal sensitivity analysis (MRSA)}

To understanding of impact of each of the parameters on the entire model, Map Removal Sensitivity Analysis (MRSA) was applied which is already established and applied in different studies (Rahman 2008; Babiker et al. 2005). In this analysis variability is analyzed by removing a layer at a time from the model and was applied in all the sub-areas. From the Eq. (2), the indices were calculated and it was found that, two parameters viz. depth to the water and impact of the vadose zone made 24.69 and $22.24 \%$ impact on the entire model. Thus it can be said that, these two parameters were responsible for $46.93 \%$ variation to the composite DRASTIC model (Table 4). The remaining parameters like recharge, aquifer media and hydraulic conductivity were associated with 18.27, 13.66 and $14.59 \%$ respectively. Soil and Topography depicted least importance in terms of variability (5.3 and $1.25 \%)$.

Table 3 Composite vulnerability index [Source: Computed]

\begin{tabular}{lll}
\hline Vulnerability indices & Vulnerability category & Area covered $(\%)$ \\
\hline$<150$ & Least & 14.13 \\
$150-159$ & Low & 30.91 \\
$160-169$ & Moderate & 25.31 \\
$170-179$ & High & 10.24 \\
$180 \&>$ & Highest & 19.41 \\
\hline
\end{tabular}


Table 4 Map removal sensitivity analysis [Source: Computed]

\begin{tabular}{llll}
\hline Layers used & Layers removed & Variation index & Cumulative variation index \\
\hline DRASTI & $\mathrm{C}$ & 14.59 & 14.59 \\
DRASTC & $\mathrm{I}$ & 22.24 & 36.84 \\
DRASIC & $\mathrm{T}$ & 1.25 & 38.08 \\
DRATIC & $\mathrm{S}$ & 5.3 & 43.38 \\
DRSTIC & $\mathrm{A}$ & 13.66 & 57.04 \\
DASTIC & $\mathrm{R}$ & 18.27 & 75.31 \\
RASTIC & $\mathrm{D}$ & 24.69 & 100 \\
\hline
\end{tabular}
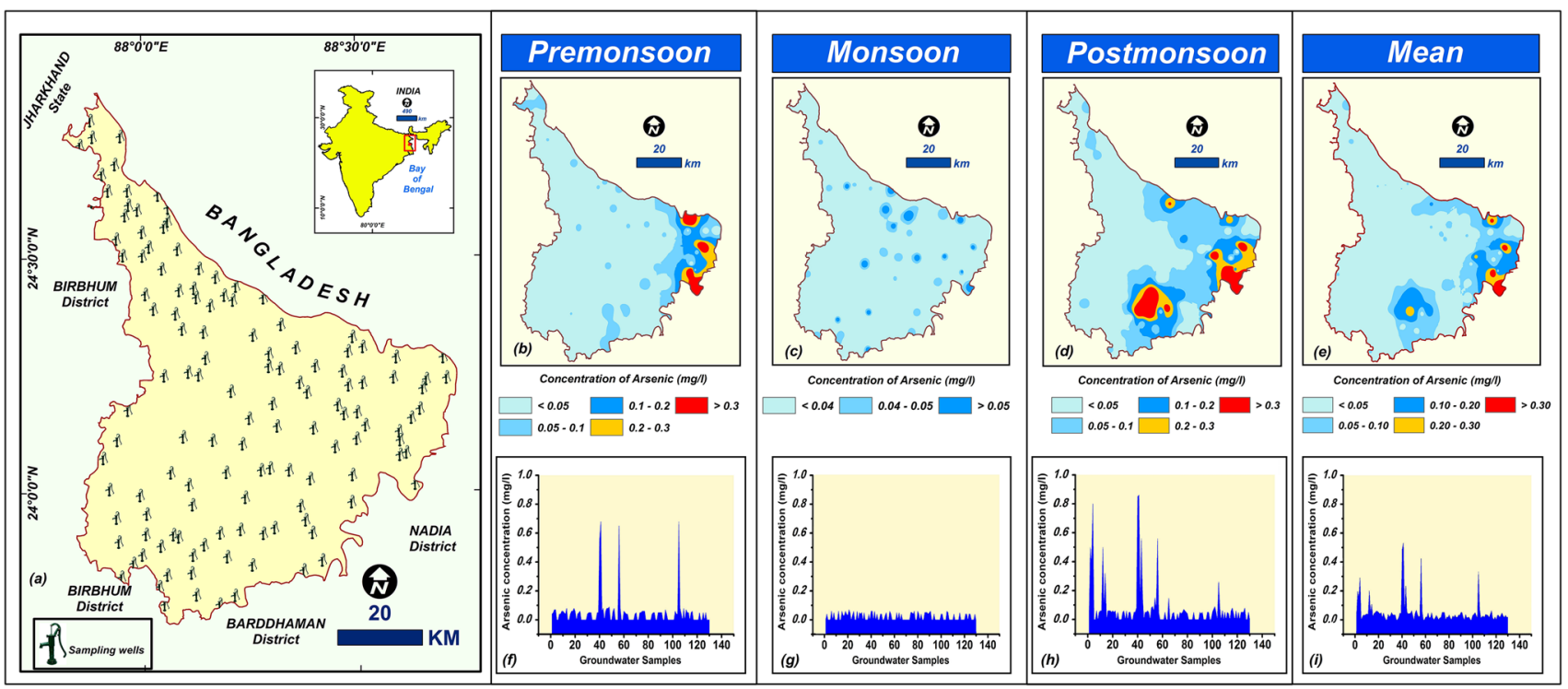

Fig. 5 Spatio-temporal pattern of arsenic concentration in groundwater

\section{Spatio-temporal pattern of arsenic concentration in groundwater and its relation to the model}

130 groundwater samples were collected during three seasons of 2010 (Fig. 5a). Concentration of arsenic in groundwater showed variation both in terms of spatial and temporal aspects. During premonsoon season, the concentration of arsenic ranged between below detection limit $(\mathrm{BDL}=0.01 \mathrm{mg} / \mathrm{l})$ to $0.68 \mathrm{mg} / \mathrm{l}$ with the mean of $0.048 \mathrm{mg} / \mathrm{l}$ touching the permissible limit set by Bureau of Indian Standard (BIS 2003) (Fig. 5b, f) while during monsoon season the maximum concentration was $0.07 \mathrm{mg} /$ 1 with low mean of $0.02 \mathrm{mg} / \mathrm{l}$ (Fig. 5c, g). Contrarily, postmonsoon season showed higher concentration than other two seasons (ranged between BDL to $0.86 \mathrm{mg} / \mathrm{l}$ ) (Fig. 5d, h). Before the rain, higher concentration of arsenic is mainly observed in the eastern segment while during rainy season, the concentration was much lesser and only in very few patches in the north central portion of the study area, relatively higher concentration of arsenic in groundwater was found. In the post monsoon season it was clearly found that the concentration was much elevated and extended in the entire eastern portion. Two major patches of higher concentration were detected in the eastern and southern segments during this period. Mean concentration of arsenic in these three season depicted patches of higher concentration in the eastern and southern segment (Fig. 5e, i).

All the sampling locations were overlaid on the generated DRASTIC model (Fig. 6). Mean concentration of arsenic of three seasons viz. premonsoon, monsoon and post monsoon was taken into considerations. $13.84 \%$ of the total sampling locations were found to be located in the highest indexed vulnerable zone $(>180)$. The next category of vulnerable index (170-179) was associated with $33.48 \%$ of the total sampling locations while $28.46 \%$ of the samples were in the third vulnerable zone. $8.46 \%$ and $15.38 \%$ of the samples were found in the last two categories.

Table 5 depicted seasonal variability of arsenic concentration in different categories of DRASTIC indices. Result showed a common factor among all the seasons 
Table 5 DRASTIC vulnerability indices and seasonal variability of arsenic concentration in groundwater (2010) [Source: Computed]

\begin{tabular}{|c|c|c|c|c|c|c|c|c|c|c|}
\hline \multirow{2}{*}{$\begin{array}{l}\text { Season } \\
\text { DRASTIC } \\
\text { index }\end{array}$} & \multicolumn{5}{|c|}{ Premonsoon } & \multicolumn{5}{|c|}{ Monsoon } \\
\hline & $\begin{array}{l}\text { Highest } \\
(180 \&>)\end{array}$ & $\begin{array}{l}\text { High } \\
(170-179)\end{array}$ & $\begin{array}{l}\text { Moderate } \\
(160-169)\end{array}$ & $\begin{array}{l}\text { Low } \\
(150-159)\end{array}$ & $\begin{array}{l}\text { Least } \\
(<150)\end{array}$ & $\begin{array}{l}\text { Highest } \\
(180 \\
\&>)\end{array}$ & $\begin{array}{l}\text { High } \\
(170-179)\end{array}$ & $\begin{array}{l}\text { Moderate } \\
(160-169)\end{array}$ & $\begin{array}{l}\text { Low } \\
(150-159)\end{array}$ & $\begin{array}{l}\text { Least } \\
(<150)\end{array}$ \\
\hline $\begin{array}{l}\text { Concentration } \\
(\mathrm{mg} / \mathrm{l})\end{array}$ & \multicolumn{5}{|c|}{$\%$ of sampling wells } & \multicolumn{5}{|c|}{$\%$ of sampling wells } \\
\hline$<0.05$ & 50.0 & 50.0 & 64.9 & 63.6 & 55.0 & 72.2 & 72.7 & 81.1 & 81.8 & 75.0 \\
\hline $0.05-0.20$ & 44.4 & 43.2 & 35.1 & 36.4 & 45.0 & 27.8 & 27.3 & 18.9 & 18.2 & 25.0 \\
\hline$>0.20$ & 5.6 & 6.8 & 0.0 & 0.0 & 0.0 & 0.0 & 0.0 & 0.0 & 0.0 & 0.0 \\
\hline \multirow{2}{*}{$\begin{array}{l}\text { Season } \\
\text { DRASTIC } \\
\text { index }\end{array}$} & \multicolumn{5}{|c|}{ Postmonsoon } & \multicolumn{5}{|l|}{ Mean } \\
\hline & $\begin{array}{l}\text { Highest } \\
(180 \& \\
>)\end{array}$ & $\begin{array}{l}\text { High } \\
(170-179)\end{array}$ & $\begin{array}{l}\text { Moderate } \\
(160-169)\end{array}$ & $\begin{array}{l}\text { Low } \\
(150-159)\end{array}$ & $\begin{array}{l}\text { Least } \\
(<150)\end{array}$ & $\begin{array}{l}\text { Highest } \\
(180 \\
\&>)\end{array}$ & $\begin{array}{l}\text { High } \\
(170-179)\end{array}$ & $\begin{array}{l}\text { Moderate } \\
(160-169)\end{array}$ & $\begin{array}{l}\text { Low } \\
(150-159)\end{array}$ & $\begin{array}{l}\text { Least } \\
(<150)\end{array}$ \\
\hline $\begin{array}{l}\text { Concentration } \\
(\mathrm{mg} / \mathrm{l})\end{array}$ & \multicolumn{5}{|c|}{$\%$ of sampling wells } & \multicolumn{5}{|c|}{$\%$ of sampling wells } \\
\hline$<0.05$ & 27.8 & 38.6 & 54.1 & 36.4 & 50.0 & 61.1 & 61.4 & 83.8 & 63.6 & 90.0 \\
\hline $0.05-0.20$ & 61.1 & 43.2 & 45.9 & 63.6 & 50.0 & 33.3 & 27.3 & 16.2 & 36.4 & 10.0 \\
\hline$>0.20$ & 11.1 & 18.2 & 0.0 & 0.0 & 0.0 & 5.6 & 11.4 & 0.0 & 0.0 & 0.0 \\
\hline
\end{tabular}

that $>90 \%$ of the samples were associated with the first two categories of the arsenic concentration $(<0.05$ and $0.05-0.20 \mathrm{mg} / \mathrm{l}$ ) (Fig. 6). In premonsoon season, $45 \%$ of the samples with concentration ranged between $0.05-0.20 \mathrm{mg} / \mathrm{l}$ were situated under the category of least vulnerable zone while $44.4 \%$ of the samples were found under the highest vulnerable zone (Fig. 7a). A contrast picture is depicted in the case of monsoon and postmonsoon season. During rainy season, most of the samples clustered around lower concentration of arsenic $(0.05 \mathrm{mg} / \mathrm{l})$ under different categories of indices (Fig. 7b). On the other hand relatively higher percentages of the samples were found in the next category of higher concentration $(0.05-0.20 \mathrm{mg} / \mathrm{l})$ in post monsoon season (Fig. 7c). Mean concentration of arsenic in all the seasons showed that $>60 \%$ of the samples were related to the least concentration $(<0.05 \mathrm{mg} / \mathrm{l})$ (Fig. 7d). Both vulnerability index of the aquifer and arsenic concentration showed that the eastern portion of the study area had higher level of risk. The probable explanation behind such condition might be due to the hydrogeological characteristics of the region. Eastern portion of the region is subjected to greater surface-subsurface water interaction due to lack of any significant impermeable layers that might controlling the geochemical characteristics of the region (Ghosh and Kanchan 2014).

\section{Correlation of arsenic concentration with DRASTIC variables}

Correlation coefficient was calculated on the basis of mean arsenic concentration of three seasons and DRASTIC variables. Results obtained from the analysis indicated the fact that the depth to the water $(+0.537)$, impact of vadose zone $(+0.437)$ and aquifer media $(+0.233)$ had good relationship with arsenic concentration. On the other hand, parameters like soil and topography depicted very weak relationship $(-0.055$ and +0.037 respectively) (Table 6). Net recharge and hydraulic conductivity were not considered as the entire region had similar characteristics in terms of the above said variables. Thus it can be depicted from the result that arsenic concentration in the groundwater and parameters like depth to the water, impact of vadose zone and aquifer media had better relationship.

\section{Conclusion}

In the present study, aquifer vulnerability of central alluvial tract of Bengal plain was assessed by using DRASTIC model developed by U.S. Environmental Protection Agency (EPA). Seven important hydrogeological parameters of Bengal alluvial tract viz. depth to the water, net recharge, aquifer media, soil media, topography, impact of vadose zone and hydraulic conductivity were incorporated and pollution potential was computed. North central portion of the region showed "highest" vulnerability while entire eastern portion was related to "high" vulnerability index. Western segment was mainly characterized by the vulnerability indices ranged from "moderate", "low" and "least", indicating increase of pollution potential from west to eastern portion of the study area. Map removal technique depicted the fact that, depth to the water and impact of vadose zone were playing important role in 


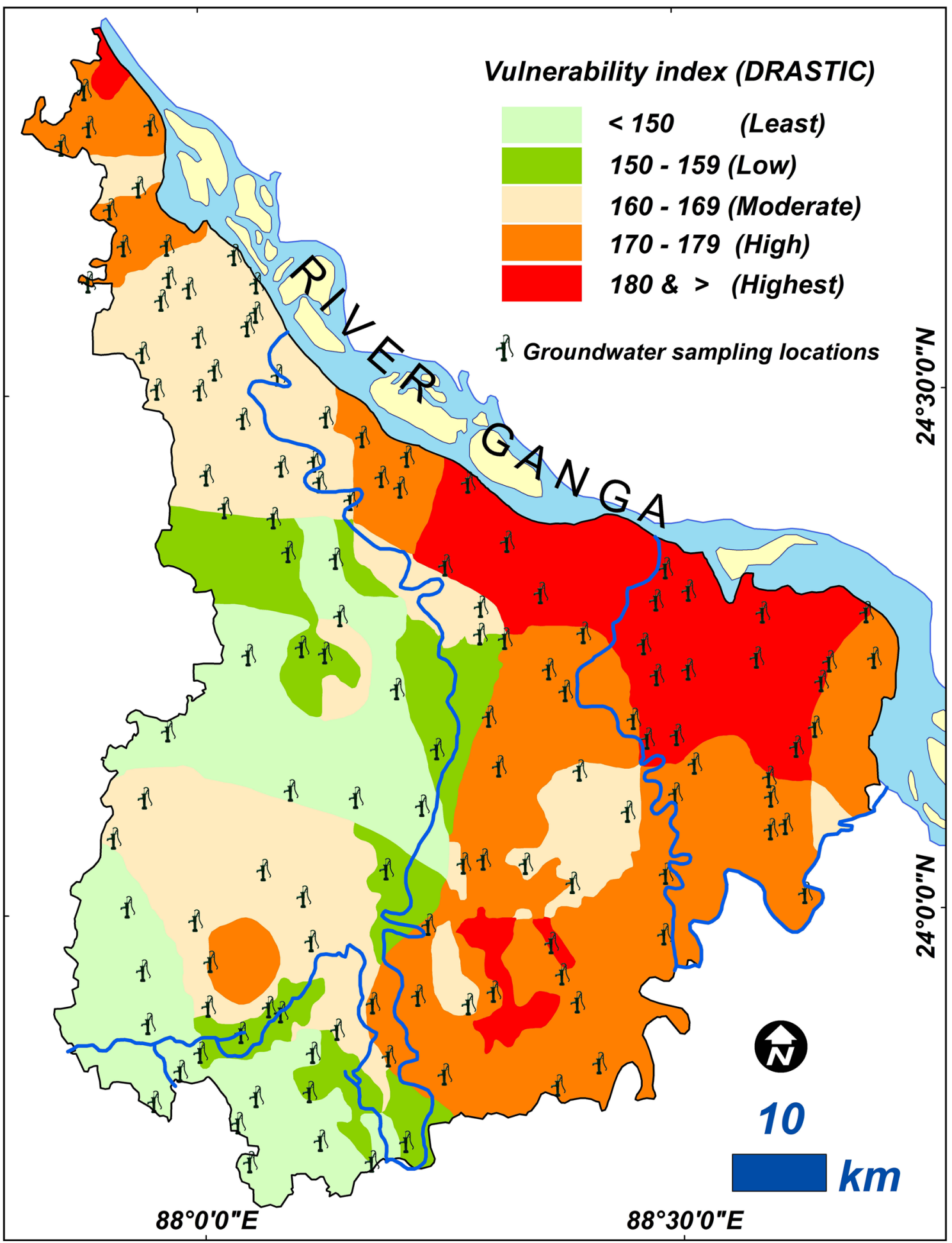

Fig. 6 Locations of the sampling wells over the DRASTIC model

controlling the subsurface hydrological characteristics of the particular region as both of the parameters were associated with higher variation indices. It was also found that a significant amount of area was under higher vulnerability. Seasonal variability of arsenic concentration and categories of DRASTIC indices depicted the fact that, during postmonsoon season, concentration was relatively higher in all the vulnerability indices while during rainy seasons the concentration was considerably lower in all the categories of indices among all the seasons. Mean arsenic 

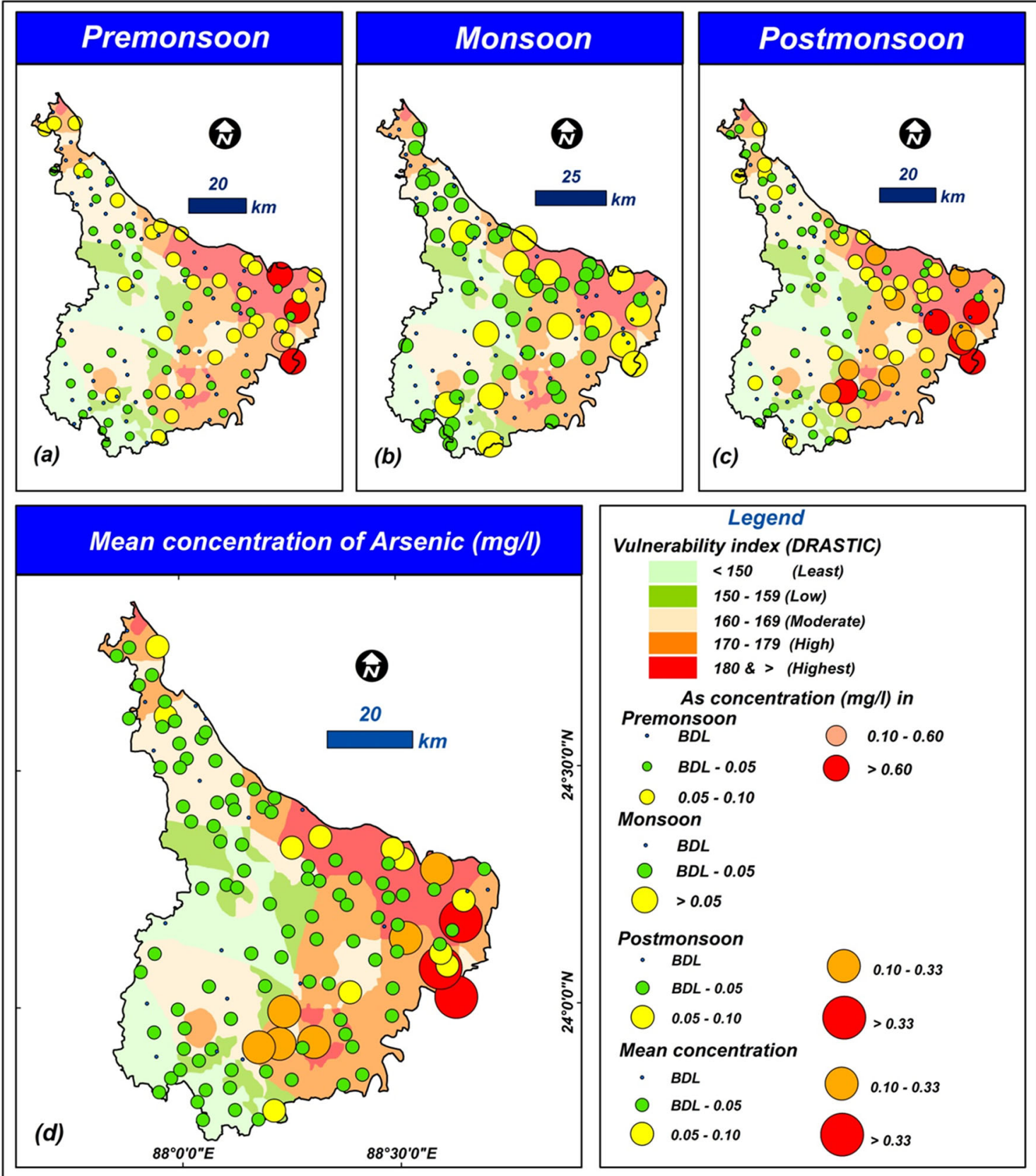

Fig. 7 Seasonal pattern of arsenic concentration in groundwater and overlay on DRASTIC model

Table 6 Correlation coefficients of DRASTIC variables with arsenic concentration [Source: Computed]

\begin{tabular}{llllll}
\hline & Depth to water & Aquifer media & Soil media & Topography & Impact of vadose zone \\
\hline Mean arsenic concentration & 0.537 & 0.233 & -0.055 & 0.037 & 0.437 \\
\hline
\end{tabular}

concentration also showed similar picture where eastern portion had higher concentration. Results obtained from the correlation coefficient between arsenic concentration and DRASTIC parameters showed better association with depth to the water, impact of aquifer media and vadose zone. In the entire study, GIS assisted not only preparing the model but also depicting the present condition of aquifer with probable explanation very efficiently and that might assists in further management of the aquifer condition of the region in future. 
Acknowledgments One of the authors (R K) is thankful to University Grants Commission, New Delhi, India for funding the Major Research Project "Arsenic in Groundwater in West Bengal-A Global Concern: Some Issues and Remedies" [F. No. 3379/2007(SR)]. Authors are thankful to the anonymous reviewers for their constructive comments in improving the quality of the paper.

\section{References}

Aller L, Bennet T, Lehr JH, Petty RJ (1987). DRASTIC: a standardized system for evaluating groundwater pollution potential using hydro geologic settings. USEPA document no. EPA/ 600/2-85-018

Anwar M, Prem CC, Rao VB (2003) Evaluation of groundwater potential of Musi River catchment using DRASTIC index model. In: Venkateshwar BR, Ram MK, Sarala CS, Raju C (eds) Hydrology and watershed management. Proceedings of the international conference 18-20, 2002. B. S. Publishers, Hyderabad, pp 399-409

Assaf H, Saadeh M (2008) Assessing water quality management options in the Upper Litani Basin, Lebanon, using an integrated GIS-based decision support system. Environ Model Softw 23(10): 1327-1337

Babiker IS, Mohamed MA, Hiyama T, Kato K (2005) A GIS-based DRASTIC model for assessing aquifer vulnerability in Kakamigahara heights, Gifu Prefecture, central Japan. Sci Total Environ 345(1):127-140

Bureau of Indian Standards (2003) Drinking Water-Specification (First Revision). IS 10500. 1991. Plus Amendment No. 1, 1993 and Amendment No. 2, 2003

Chandrashekhar H, Adiga S, Lakshminarayana V, Jagdeesha CJ, Nataraju C (1999) A case study using the model 'DRASTIC' for assessment of groundwater pollution potential. In: Proceedings of the ISRS national symposium on remote sensing applications for natural resources, June 19-21, Bangalore

Chitsazan M, Akhtari Y (2009) A GIS-based DRASTIC model for assessing aquifer vulnerability in Kherran Plain, Khuzestan, Iran. Water Resour Manag 23(6):1137-1155

Civita M, De Maio M (2004) Assessing and mapping groundwater vulnerability to contamination: the Italian" combined" approach. Geofísica Internacional 43(4):513-532

District Census Hand Book (2001) Murshidabad District, Census of India

District Planning Map Series (2002) National Atlas \& thematic mapping organisation. Department of Science \& Technology, Government of India, Murshidabad, West Bengal

District Resource Map (2008) Murshidabad, West Bengal

Dixon B (2005) Groundwater vulnerability mapping: a GIS and fuzzy rule based integrated tool. Appl Geogr 25(4):327-347

Foster SSD (1987) Fundamental concepts in aquifer vulnerability, pollution risk and protection strategy. In: Van Duijevenboden W, Van Waegeningh HG (eds) Vulnerability of soil and groundwater to pollutants, TNO Committee on Hydrogeological Research, Proceedings and Information, The Hague, vol 38, pp 69-86

Fraga CM, Fernandes LFS, Pacheco FAL, Reis C, Moura JP (2013) Exploratory assessment of groundwater vulnerability to pollution in the Sordo River Basin, Northeast of Portugal. Rem Revista Escola de Minas 66(1):49-58
Fritch TG, Mcknight CL, Yelderman JC Jr, Arnold JG (2000) An aquifer vulnerability assessment of the Paluxy aquifer, central Texas, USA, using GIS and a modified DRASTIC approach. Environ Manag 25(3):337-345

Ghosh T, Kanchan R (2014) Geoenvironmental appraisal of groundwater quality in Bengal alluvial tract, India: a geochemical and statistical approach. Environ Earth Sci 72(7):2475-2488

Groundwater Information Booklet (2007) District Murshidabad (Arsenic Affected Area) West Bengal. Central Groundwater Board, Eastern Region, Kolkata

Herlinger Jr R, Pedro VA (2007) Groundwater vulnerability assessment in coastal plain of Rio Grande do Sul State, Brazil, using drastic and adsorption capacity of soils

Hvorslev MJ (1951) Time lag and soil permeability in ground-water observations, Bull. No. 36, Waterways Exper. Sta. Corps of Engrs, U.S. Army, Vicksburg, Mississippi, pp 1-50

Knox RC, Sabatini DA, Canter LW (1993) Subsurface transport and fate processes. Lewis Publishers, USA

Lee S (2003) Evaluation of waste disposal site using the DRASTIC system in Southern Korea. Environ Geol 44(6):654-664

Margane A (2003) Management and protection and sustainable use of groundwater and soil resources in the Arab region, guideline for groundwater vulnerability mapping and risk assessment for susceptibility of groundwater resources to contamination, vol 4 . Project no. 1996.2189.7

Napolitano P (1995) GIS for aquifer vulnerability assessment in the Piana Campana, southern Italy, using the DRASTIC and SINTACS methods. M.Sc. thesis, ITC, Enschede, The Netherlands (unpublished)

Napolitano P, Fabbri AG (1996) Single-parameter sensitivity analysis for aquifer vulnerability assessment using DRASTIC and SINTACS. IAHS Publ Ser Proc Rep Intern Assoc Hydrol Sci 235:559-566

Panagopoulos GP, Antonakos AK, Lambrakis NJ (2006) Optimization of the DRASTIC method for groundwater vulnerability assessment via the use of simple statistical methods and GIS. Hydrogeol J 14(6):894-911

Rahman A (2008) A GIS based DRASTIC model for assessing groundwater vulnerability in shallow aquifer in Aligarh. India. Applied Geography 28(1):32-53

Ravenscroft P, Brammer H, Richards K (2009) Arsenic pollution: a global synthesis, vol 28. Wiley, UK

Saha D, Alam F (2014) Groundwater vulnerability assessment using DRASTIC and Pesticide DRASTIC models in intense agriculture area of the Gangetic plains India. Environ Monit Assess 186(12):8741-8763

Todd DK, Mays LW (1980) Groundwater hydrology. Wiley, India

US EPA (1985) DRASTIC: a standard system for evaluating groundwater potential using hydrogeological settings. Ada, Oklahoma WA/EPA Series

Van Stempvoort DR, Fritz P, Reardon EJ (1992) Sulfate dynamics in upland forest soils, central and southern Ontario, Canada: stable isotope evidence. Appl Geochem 7(2):159-175

Wen X, Wu J, Si J (2009) A GIS-based DRASTIC model for assessing shallow groundwater vulnerability in the Zhangye Basin, northwestern China. Environ Geol 57(6):1435-1442 